Journal of Advanced Research in Applied Sciences and Engineering Technology

\title{
Study on The Factors and Effects of Noise Pollution at Construction Site in Klang Valley
}

\author{
Chow Yi Feng ${ }^{1}$, Nur Ilya Farhana Md Noh ${ }^{1,}{ }^{*}$, Ramez Al Mansob ${ }^{1}$ \\ 1 Department of Civil Engineering, Faculty of Engineering, UCSI University, 56000 Cheras, Kuala Lumpur, Malaysia
}

\section{ABSTRACT}

\begin{abstract}
Noise Pollution is the high intensity of sound that is unnecessary and will cause harmful or danger towards human or nearby ecosystem. However, the occurrence of noise pollution is getting worse due to the process of country development. Noise pollution at construction site has become one of the noise pollution contributors in urban area where development in keep on going with the needs of construction projects. Area of study had been targeted at Klang Valley, Malaysia since it was one of the developing areas that consist huge amount of construction projects. Noise pollution produced at construction site is harmful to the health of those who involved in the construction projects and stay at the site for a long period of works. Thus, the main objectives of this study are to determine the factor of noise pollution at construction site and the effects of the noise towards those parties who involve such as engineer, contractor etc. The solutions to prevent or decrease the noise pollution at construction site were determined to help reducing its bad effects. Approximately 60 respondents had been collected in this survey to determine the most significant factor, effect and solution for noise pollution at construction site around Klang Valley. Based on the finding of this study, the significant factor caused noise pollution at construction site is due to heavy machinery operating. Respondents agreed that the noise pollution major affect is sleep disturbance. The significant solution against noise pollution at construction site is by applying muffler or silencer on construction machinery and equipment.
\end{abstract}

Keywords:

Noise Pollution; Construction Site; Klang

Valley

Copyright $@ 2020$ PENERBIT AKADEMIA BARU - All rights reserved

\section{Introduction}

Klang Valley as a populated area around Peninsular Malaysia which consist of approximately 7.9 million people [1]. Pollution is unavoidable in populated area whereby development of each sector is growing fast. Noise pollution is one of the pollutions that highly affect the ecosystem of public. Daily work will be interrupted by noise pollution that situated nearby. Construction activities occurs in everywhere around Klang Valley that helps in generating noise pollution whereby development is needed. Construction work is one of the main contributors of noise pollution where the noise produced is in long term period and with mixture of varies type sound [2]. The allowable noise limit will help to detect if the noise level is higher than the allowable limit in order to prevent noise pollution. Occupational Safety and Health Administration (OSHA) permissible exposure noise limit is 90 decibel (dBA) [3]. Noise produced higher than $90 \mathrm{dBa}$ will cause harmful to human health in physical

\footnotetext{
* Corresponding author.

E-mail address: Ilya@ucsiuniversity.edu.my
}

https://doi.org/10.37934/araset.20.1.1826 
or mentally. Employee that works in construction site expose to noise pollution in long time period that will cause injuries towards their health. Sixteen percent of worldwide disabling hearing loss was due to occupational noise [4].

There are lots of factor that cause the noise pollution in a construction site. Noises from machinery or handwork construction such as piling, welding, knocking, hammering or even material transportation. Different level of noises to and from the construction site within certain period depends on the type or stage of job occurring at the site. Different job uses different equipment or instrument to perform the work. Hence this shows that noise pollution at construction site is mixed with varies type of noises [5]. Studies shows that the impact of noise pollution at construction site towards construction workers is greater than public or nearby residences [6]. These noises pollution had caused more than half a million workers working at a condition which the exposure of condition might cause danger or hazard towards workers. However, federal and state Occupational Safety \& Health Administration (OSHA) Program only able to provide little incentive to protect workers against noise-induced hearing loss [7].

Noise had been concluded as a disturbance for a good sleep neither primary nor secondary sleep. It will interrupt or decrease the sleeping time. [8] state that when a person difficult to fall asleep, having different sleeping patterns and awakening are considered as primary effects. The aftermath of interrupted sleep is considered as secondary effects. Fatigue decrease of immune system and effect performance is few examples of secondary effects. Besides than primary and secondary effect, physiological effect will also occur such as blood pressure, heart rate and finger amplitude will increase [9]. [10] said that people who lives at high population and high level of noise surrounding urban places will have greater chances on increasing neuroticism, having high sensitivity of noise sensation and even noise annoyance.

In construction industry, workers are normally being forced to perform their task in a bad working condition such as long time period under the sun, exposure of high level of sound intensity and exposure of dust and chemical all-days long. Besides that, 17 long periods of working time with the poor condition and noise pollution makes workers stress level to be increase eventually [11]. Stress is the main factor of causing cardiovascular diseases and one of the factors that cause stress is unwanted noises or noise pollution [12][13]. Stress Hormones such as noradrenalin, adrenaline and cortisol are affected with high level of continuous noises. Both directly or indirectly ways of disturbance activities such as construction works also will causes stress. Hormones changes coherence with other biological risk factor such as hypertension. When hypertension occurs, there will also be changes in glucose level and blood lipids. These risk factor will keep on increasing the risk of getting cardiovascular diseases. Thus, stress and cardiovascular disease will come together when they face these issues. [14] state that noise pollution cause mentally damages such as annoyance, mentality stress, sleep disturbance, immune effect, cardiovascular disease, unable to focus and the most affect is loss of hearing. According to [15], sixteen percentage of worldwide disabling hearing loss in adult is due to occupational noise. Thus, this contributed to statement state that noise pollution at construction affected workers more than public or nearby ecosystem.

Thus, factors and effects of noise pollution should be determined and be aware by workers so that the damage can be minimize with solution or protection. The area of research for this paper is focused in Klang Valley construction industry.

\section{Methodology}

Questions were separated into two parts which are point scale and written form. Besides that, it is consisting of few parts such as factor of sound pollution at construction site, effects of sound 
pollution towards participant, suggestion on preventing sound pollution and noise level exposed to the participant. Participant will rate the factor and effect that affected the most to them and they could suggest any solution to help them or make their working surrounding less expose to sound pollution. No name is needed to be written down in the questionnaire so that information of participant is remained confidential and there will be no other people noticed the identity of participant. Only basic information is needed to be noted in questionnaire such as gender, age and role or position. They are required to rate the factor and effects according to scale 1 to 5 whereby 1 representing strongly disagree and 5 representing strongly agreed. Solution able to be provided by respondent with their professionalism towards construction industry sector.

Collection of data should be done after distributing to respondents. Data has been analyzed through Statistical Package for the Social Sciences (SPSS) software. This software will determine the most significant factor, effect and solution of noise pollution at construction site with the data collected from respondents. After Analysis of data was done, recommendation of solution should be determined according to analyze data. Conclusion regarding factor, effect and solution of noise pollution should be determining and report was recorded for future studies.

\section{Results}

Quantitative data collection for research through questionnaire survey and 60 respondent participants in this questionnaire survey. Questionnaire was analysed using Statistical Package for The Social Sciences (SPSS) software, Version 25.

\subsection{Reliability Test Data}

Reliability of data is the most important in data analysis whereby it shows the data are trustable or not. Cronbach Alpha with greater than 0.6 are considered as valid and reliable. Throughout data collection, Cronbach Alpha of data was in between 0.621 to 0.82 whereby all topics are reliable. Table 1 shows the reliability of each topics.

Table 1

Test of Reliability

\begin{tabular}{lcc}
\multicolumn{1}{c}{ Topic } & Cronbach Alpha & No. of Item \\
\hline $\begin{array}{l}\text { Part } 2.1 \text { the factors that causes noise pollution at } \\
\text { construction site }\end{array}$ & 0.621 & 4 \\
$\begin{array}{l}\text { Part } 2.2 \text { the types of work that contribute } \\
\text { in noise pollution at construction site }\end{array}$ & 0.651 & 6 \\
$\begin{array}{l}\text { Part } 3 \text { the physical and mentally effects that } \\
\text { caused by noise pollution at construction site. } \\
\text { Part } 4 \text { the effects of noise pollution at }\end{array}$ & 0.788 & 7 \\
$\begin{array}{l}\text { construction site } \\
\text { Part } 5 \text { the solution on the physical and mentally } \\
\text { effects that caused by noise pollution at } \\
\text { construction site. }\end{array}$ & 0.728 & 3 \\
& 0.820 & 9 \\
\hline
\end{tabular}




\subsection{Identify Factors that Cause Noise Pollution at Construction Site}

Total of four factor identify in this research which are operation construction equipment and device, heavy machinery operating, vehicle transporting materials and loud voice communication. After analysis of data, most significant factor of noise pollution at construction site was heavy machinery operating with mean $=4.23$ and $S D=0.673$. Following by operation construction equipment and device (mean $=3.92, \mathrm{SD}=0.671$ ), vehicle transporting materials (mean=3.55, $\mathrm{SD}=0.928$ ) and lastly loud voice communication (mean=2.72, $\mathrm{SD}=0.940$ ). Mostly respondent agreed in heavy machinery operating causes the most noise pollution at construction site while loud voice communication rarely contribute in noise pollution whereby communication does not last long and does not travel far. Table 2 shows the frequency and percentage for factor that causes noise pollution at construction site.

\section{Table 2}

Frequency and Percentage for Factors that Cause Noise Pollution at Construction Site

\begin{tabular}{lccccccc}
\hline \multicolumn{1}{c}{ Factors } & 1 & 2 & 3 & 4 & 5 & Mean & SD \\
\hline Operation construction & 0 & 2 & 10 & 39 & 9 & 3.92 & 0.671 \\
equipment and device & & $(3.3 \%)$ & $(16.7 \%)$ & $(65 \%)$ & $(15 \%)$ & & \\
Heavy machinery operating & 1 & 0 & 2 & 38 & 19 & 4.23 & 0.673 \\
& $(1.7 \%)$ & & $(3.3 \%)$ & $(63.3 \%)$ & $(31.7 \%)$ & & \\
Vehicle Transporting Materials & 1 & 10 & 9 & 35 & 5 & 3.55 & 0.928 \\
& $(1.7 \%)$ & $(16.7 \%)$ & $(15 \%)$ & $(58.3 \%)$ & $(8.3 \%)$ & & \\
Loud voice communication & 3 & 25 & 21 & 8 & 3 & 2.72 & 0.940 \\
Overall & $(5 \%)$ & $(41.7 \%)$ & $(35 \%)$ & $(13.3 \%)$ & $(5 \%)$ & & \\
& & & & & & 3.604 & 0.492 \\
\hline
\end{tabular}

\subsection{Identify Effects that Cause Noise Pollution at Construction Site}

There are seven effects had been determined which are cardiovascular diseases, overstress, hearing loss, sleep disturbance, unable to focus, miscommunication or misinterpret information and change in blood circulation and skin temperature. Table 3 shows the frequency and percentage for effects that causes by noise pollution at construction site. Sleep disturbance (mean=4.05, $\mathrm{SD}=0.675$ ) had been chosen as the most significant effect of noise pollution at construction site following with unable to focus (mean=4.0, $S D=0.638$ ) and hearing loss (mean=3.98, $S D=0.651$ ). Noise pollution at construction site had caused sleep disturbance to workers that work at construction site and also nearby residences whenever construction is carried on all day and night. Residences unable to sleep with the high frequency noise produced from construction site. Change in blood circulation and skin temperature (mean=2.72, SD=1.059) consist of most least significant effect of noise pollution. This is due to lack of awareness and information to workers. Workers might think of other reason instead of noise pollution when circumstances occur.

\subsection{Identify Solution on Effects that Cause by Noise Pollution at Construction Site}

A total of nine solutions are found throughout research and Table 4 shows the frequency and percentage for solutions on effects that causes by noise pollution at construction site. Applying silencer or muffler on construction machinery and equipment had been analyse as most significant solution on effects of noise pollution at construction site with mean $=4.17$ and $S D=0.526$ followed by well maintaining construction equipment and device (mean=4.1, SD=0.602). Equipment or 
device with well maintaining will produce lesser noise compare to old version machinery equipment. When machinery or equipment equipped with muffler or silencer, the noise produce will be highly reduced and rarely cause high frequency noise. Hiring more workers to reduce exposure time of noise pollution (mean $=3.42, S D=0.962$ ) has the least mean whereby it will also cause the project cost to be increased.

Table 3

Frequency and Percentage for Effects that Cause Noise Pollution at Construction Site

\begin{tabular}{|c|c|c|c|c|c|c|c|}
\hline Effects & 1 & 2 & 3 & 4 & 5 & Mean & SD \\
\hline Cardiovascular Disease & $\begin{array}{c}3 \\
(5 \%)\end{array}$ & $\begin{array}{c}19 \\
(31.7 \%)\end{array}$ & $\begin{array}{c}22 \\
(36.7 \%)\end{array}$ & $\begin{array}{c}11 \\
(18.3 \%)\end{array}$ & $\begin{array}{c}5 \\
(8.3 \%)\end{array}$ & 2.93 & 1.023 \\
\hline Over Stress & $\begin{array}{c}1 \\
(1.7 \%)\end{array}$ & $\begin{array}{c}1 \\
(1.7 \%)\end{array}$ & $\begin{array}{c}9 \\
(15 \%)\end{array}$ & $\begin{array}{c}41 \\
(68.3 \%)\end{array}$ & $\begin{array}{c}8 \\
(13.3 \%)\end{array}$ & 3.90 & 0.706 \\
\hline Hearing Loss & 0 & $\begin{array}{c}2 \\
(3.3 \%)\end{array}$ & $\begin{array}{c}7 \\
(11.7 \%)\end{array}$ & $\begin{array}{c}41 \\
(68.3 \%)\end{array}$ & $\begin{array}{c}10 \\
(16.7 \%)\end{array}$ & 3.98 & 0.651 \\
\hline Sleep disturbance & 0 & $\begin{array}{c}2 \\
(3.3 \%)\end{array}$ & $\begin{array}{c}6 \\
(10 \%)\end{array}$ & $\begin{array}{c}39 \\
(65 \%)\end{array}$ & $\begin{array}{c}13 \\
(21.7 \%)\end{array}$ & 4.05 & 0.675 \\
\hline Unable to focus & 0 & $\begin{array}{c}2 \\
(3.3 \%)\end{array}$ & $\begin{array}{c}6 \\
(10 \%)\end{array}$ & $\begin{array}{c}42 \\
(70 \%)\end{array}$ & $\begin{array}{c}10 \\
(16.7 \%)\end{array}$ & 4.00 & 0.638 \\
\hline $\begin{array}{l}\text { Miscommunication of } \\
\text { misinterpret information }\end{array}$ & $\begin{array}{c}1 \\
(1.7 \%)\end{array}$ & $\begin{array}{c}20 \\
(33.3 \%)\end{array}$ & $\begin{array}{c}9 \\
(15 \%)\end{array}$ & $\begin{array}{c}24 \\
(40 \%)\end{array}$ & $\begin{array}{c}6 \\
(10 \%)\end{array}$ & 3.23 & 1.079 \\
\hline $\begin{array}{l}\text { Change in blood circulation and } \\
\text { body temperature }\end{array}$ & $\begin{array}{c}4 \\
(6.7 \%)\end{array}$ & $\begin{array}{c}28 \\
(46.7 \%)\end{array}$ & $\begin{array}{c}13 \\
(21.7 \%)\end{array}$ & $\begin{array}{c}11 \\
(18.3 \%)\end{array}$ & $\begin{array}{c}4 \\
(6.7 \%)\end{array}$ & 2.72 & 1.059 \\
\hline Overall & & & & & & 3.545 & 0.459 \\
\hline
\end{tabular}

\section{Table 4}

Frequency and Percentage for Solution on Effects that Cause Noise Pollution at Construction Site

\begin{tabular}{|c|c|c|c|c|c|c|c|}
\hline Solutions & 1 & 2 & 3 & 4 & 5 & Mean & SD \\
\hline \multirow{4}{*}{$\begin{array}{l}\text { Wear PPE } \\
\text { Prediction of Noise Pollution } \\
\text { during planning stage } \\
\text { Applying silencer or muffler on } \\
\text { machinery and equipment } \\
\text { Construct noise barrier around } \\
\text { construction site }\end{array}$} & $\begin{array}{c}1 \\
(1.7 \%)\end{array}$ & $\begin{array}{c}6 \\
(10 \%)\end{array}$ & $\begin{array}{c}10 \\
(16.7 \%)\end{array}$ & $\begin{array}{c}28 \\
(46.7 \%)\end{array}$ & $\begin{array}{c}15 \\
(25 \%) \\
\end{array}$ & 3.83 & 0.977 \\
\hline & $\begin{array}{c}1 \\
(1.7 \%)\end{array}$ & $\begin{array}{c}6 \\
(10 \%) \\
\end{array}$ & $\begin{array}{c}9 \\
(15 \%)\end{array}$ & $\begin{array}{c}30 \\
(50 \%)\end{array}$ & $\begin{array}{c}14 \\
(23.3 \%)\end{array}$ & 3.83 & 0.960 \\
\hline & 0 & 0 & $\begin{array}{c}4 \\
(6.7 \%)\end{array}$ & $\begin{array}{c}42 \\
(70 \%)\end{array}$ & $\begin{array}{c}14 \\
(23.3 \%)\end{array}$ & 4.17 & 0.526 \\
\hline & 0 & $\begin{array}{c}1 \\
(1.7 \%)\end{array}$ & $\begin{array}{c}6 \\
(10 \%)\end{array}$ & $\begin{array}{c}40 \\
(66.7 \%)\end{array}$ & $\begin{array}{c}13 \\
(21.7 \%)\end{array}$ & 4.08 & 0.619 \\
\hline \multirow{4}{*}{$\begin{array}{l}\text { Hire more workers to reduce the } \\
\text { exposure time to noise pollution } \\
\text { Choose quitter model of } \\
\text { equipment or device } \\
\text { Setting limitation on time period } \\
\text { and frequency of noise pollution } \\
\text { Replacing old machinery with new } \\
\text { model }\end{array}$} & $\begin{array}{c}2 \\
(3.3 \%)\end{array}$ & $\begin{array}{c}10 \\
(16.7 \%)\end{array}$ & $\begin{array}{c}13 \\
(21.7 \%)\end{array}$ & $\begin{array}{c}31 \\
(51.7 \%)\end{array}$ & $\begin{array}{c}4 \\
(6.7 \%)\end{array}$ & 3.42 & 0.962 \\
\hline & 0 & $\begin{array}{c}2 \\
(3.3 \%)\end{array}$ & $\begin{array}{c}5 \\
(8.3 \%)\end{array}$ & $\begin{array}{c}43 \\
(71.7 \%)\end{array}$ & $\begin{array}{c}10 \\
(16.7 \%)\end{array}$ & 4.02 & 0.624 \\
\hline & 0 & $\begin{array}{c}6 \\
(10 \%)\end{array}$ & $\begin{array}{c}16 \\
(26.7 \%)\end{array}$ & $\begin{array}{c}26 \\
(43.3 \%)\end{array}$ & $\begin{array}{c}12 \\
(20 \%)\end{array}$ & 3.73 & 0.899 \\
\hline & 0 & $\begin{array}{c}2 \\
(3.3 \%)\end{array}$ & $\begin{array}{c}15 \\
(25 \%) \\
\end{array}$ & $\begin{array}{c}35 \\
(58.3 \%)\end{array}$ & $\begin{array}{c}8 \\
(13.3 \%)\end{array}$ & 3.82 & 0.701 \\
\hline \multirow{2}{*}{$\begin{array}{l}\text { Well maintaining construction } \\
\text { equipment } \\
\text { Overall }\end{array}$} & 0 & $\begin{array}{c}1 \\
(1.7 \%)\end{array}$ & $\begin{array}{c}5 \\
(8.3 \%) \\
\end{array}$ & $\begin{array}{c}41 \\
(68.3 \%)\end{array}$ & $\begin{array}{c}13 \\
(21.7 \%)\end{array}$ & 4.10 & 0.602 \\
\hline & & & & & & 3.75 & 0.798 \\
\hline
\end{tabular}




\section{Conclusions}

Noise Pollution was unavoidable in developing country or area although it causes varies type of effects towards workers or residences nearby. Determining the most significant factor of noise pollution at construction site so that prevention can be done towards the factor. The most significant factor of noise pollution at construction site was heavy machinery operating where they produce high frequency of noise. The most significant effect cause by noise pollution was sleep disturbance since machinery will be operating in long time period and workers or residence unable to rest well with the high frequency noise produced. Thus, applying silencer or muffler was the best choice to overcome the factor of noise pollution. When machinery is equipped with silencer or muffler, noise frequency produced will highly reduce and workers and residences nearby able to rest well.

\section{References}

[1] Nelson, Deborah Imel, Robert Y. Nelson, Marisol Concha-Barrientos, and Marilyn Fingerhut. "The global burden of occupational noise-induced hearing loss." American journal of industrial medicine 48, no. 6 (2005): 446-458. https://doi.org/10.1002/ajim.20223

[2] World Gazetteer: Malaysia - largest cities (per geographical entity)". World-gazetteer.com. 9 February 2013. Archived from original on 9 February 2013.

[3] InsulTech, 2016. GenSet Sound Attenuation Basics - InsulTech. Retrieved from <http://www.insultech.com/index/2016/04/18/genset-sound-attenuation/> [Accessed 30 Jan 2019]

[4] Birkner, Jeff. "Noise in Construction Construction sites present unique problems that are not present in other work situations in general industry." Occupational Hazards 3, no. 7 (2010): 35.

[5] Burkhart, G., and P. Sieber Schulte. "W. 1993." Job tasks, potential exposures, and health risks of laborers employed in the construction industry. Ame. Jour. of Ind. Med 24, no. 4: 413-425.

https://doi.org/10.1002/ajim.4700240407

[6] Koushki, P. A., N. Kartam, and N. Al-Mutairi. "Workers' perceptions and awareness of noise pollution at construction sites in Kuwait." Civil Engineering and Environmental Systems 21, no. 2 (2004): 127-136.

https://doi.org/10.1080/10286600310001642839

[7] Verbeek, Jos H., Erik Kateman, Thais C. Morata, Wouter A. Dreschler, and Christina Mischke. "Interventions to prevent occupational noise-induced hearing loss: a Cochrane systematic review." International journal of audiology 53, no. sup2 (2014): S84-S96.

https://doi.org/10.3109/14992027.2013.857436

[8] Fuller, Richard A., Philip H. Warren, and Kevin J. Gaston. "Daytime noise predicts nocturnal singing in urban robins." Biology letters 3, no. 4 (2007): 368-370.

https://doi.org/10.1098/rsbl.2007.0134

[9] Goines, Lisa, and Louis Hagler. "Noise pollution: a modem plague." South Med J 100, no. 3 (2007): 287-94.

https://doi.org/10.1097/SMJ.0b013e3180318be5

[10] Jakovljević, Branko, Goran Belojević, Katarina Paunović, and Vesna Stojanov. "Road traffic noise and sleep disturbances in an urban population: cross-sectional study." Croatian medical journal 47, no. 1 (2006): 125-133.

[11] Leung, Mei-yung, Yee-Shan Chan, and Ka-Wing Yuen. "Impacts of stressors and stress on the injury incidents of construction workers in Hong Kong." Journal of Construction Engineering and Management 136, no. 10 (2010): 1093-1103.

https://doi.org/10.1061/(ASCE)CO.1943-7862.0000216

[12] Ising, Hartmut, and Barbara Kruppa. "Health effects caused by noise: evidence in the literature from the past 25 years." Noise and Health 6, no. 22 (2004): 5.

[13] Babisch, Wolfgang. "Transportation noise and cardiovascular risk: updated review and synthesis of epidemiological studies indicate that the evidence has increased." Noise and Health 8, no. 30 (2006): 1.

https://doi.org/10.4103/1463-1741.32464

[14] Fernández, Marcos D., Samuel Quintana, Noelia Chavarría, and José A. Ballesteros. "Noise exposure of workers of the construction sector." Applied Acoustics 70, no. 5 (2009): 753-760.

https://doi.org/10.1016/i.apacoust.2008.07.014

[15] Suter, Alice H. "Construction noise: exposure, effects, and the potential for remediation; a review and analysis." Aiha Journal 63, no. 6 (2002): 768-789. 


\section{Supplementary Data: Survey Form}

\section{Noise Pollution on Construction Site Survey Form}

Klang Valley is a fast development area that consist of various project construction. Noise produced at construction site is one of the main sources of noise pollution that might causes disruption to neighbourhood. Thus, a Study was done about the Factor and Effects of Noise Pollution at Construction Site in Klang Valley.

The Objectives of the study Consist of:

1. To determine the factors of noise pollution at construction industry

2. To determine the effects of noise pollution at construction site

3. To recommend a solution to reduce the noise pollution at construction site around Klang Valley

I am aware that information needed by the researcher. I agreed and voluntary to provide the information and opinion towards the construction management studies. I granted the authority to withdraw my response towards this survey at any time. Hereby, I will participate in this survey.

Part 1: Biographical of Respondent

Age:

Gender:

\begin{tabular}{|l|l|}
\hline Male & \\
\hline Female & \\
\hline
\end{tabular}

Highest Education Qualification:

\begin{tabular}{|l|l|}
\hline Primary Education & \\
\hline Secondary Education & \\
\hline Pre-University & \\
\hline Bachelor Degree & \\
\hline Master's Degree & \\
\hline Doctorate Degree & \\
\hline Other: & \\
\hline
\end{tabular}

Experiences in Construction Industry:

\begin{tabular}{|l|l|}
\hline Less Than 2 Years & \\
\hline $2-5$ Years & \\
\hline $6-10$ Years & \\
\hline $11-15$ Years & \\
\hline $16-20$ Years & \\
\hline More Than 20 Years & \\
\hline
\end{tabular}

Name of Company/Organization:

Company Nature: 


\begin{tabular}{|l|l|}
\hline Contractor & \\
\hline Developer & \\
\hline Supplier & \\
\hline Consultant & \\
\hline Other: & \\
\hline
\end{tabular}

Job Position:

eg: Project Director, Site Worker

Site Location:

eg: Sungai Buloh

Project Name:

eg: MRT V201

Part 2: Factors of Noise Pollution at Construction Site

1. Following are the factors that causes noise pollution at construction site around Klang Valley. Please rate appropriate as below:

Note: 1 = Strongly Disagree, $2=$ Disagree, $3=$ Neutral, $4=$ Agree, $5=$ Strongly Agree

\begin{tabular}{|l|l|l|l|l|l|}
\hline Operation Construction Equipment or Device & 1 & 2 & 3 & 4 & 5 \\
\hline Heavy Machinery Operating & & & & & \\
\hline Vehicle Transporting Materials & & & & & \\
\hline Loud Voice Communication & & & & & \\
\hline
\end{tabular}

2. Following are types of works that contribute in noise pollution at Construction Site around Klang Valley. Please rate appropriate as below:

Note: 1 = Strongly Disagree, 2 = Disagree, $3=$ Neutral, $4=$ Agree, $5=$ Strongly Agree

\begin{tabular}{|l|l|l|l|l|l|}
\hline Plastering Work & 1 & 2 & 3 & 4 & 5 \\
\hline Earth Work or Soil Excavation & & & & & \\
\hline Concrete Work or Drilling & & & & & \\
\hline Scaffold Work or Lifting Work & & & & & \\
\hline Building Demolition or Explosion & & & & & \\
\hline Electrical or Piping Work & & & & & \\
\hline
\end{tabular}

Part 3: Effects of Noise Pollution at Construction Site

1. Following are the physical and mentally effects that caused by noise pollution at construction site around Klang Valley. Please rate appropriate as below:

Note: 1 = Strongly Disagree, $2=$ Disagree, $3=$ Neutral, $4=$ Agree, $5=$ Strongly Agree

\begin{tabular}{|l|l|l|l|l|l|}
\hline Cardiovascular Disease & 1 & 2 & 3 & 4 & 5 \\
\hline Over Stress & & & & & \\
\hline Hearing Loss & & & & & \\
\hline Sleep Disturbance & & & & & \\
\hline
\end{tabular}




\begin{tabular}{|l|l|l|l|l|l|}
\hline Unable to Focus & & & & & \\
\hline Miscommunication/ Misinterpret information & & & & & \\
\hline Change in Blood Circulation and Skin Temperature & & & & & \\
\hline
\end{tabular}

2. The following are effects of noise pollution at construction site around Klang Valley on construction project. Please rate appropriate as below:

Note: 1 = Strongly Disagree, $2=$ Disagree, $3=$ Neutral, $4=$ Agree, $5=$ Strongly Agree

\begin{tabular}{|l|l|l|l|l|l|}
\hline Project Delay & 1 & 2 & 3 & 4 & 5 \\
\hline Project Cost Increment & & & & & \\
\hline Project Quality & & & & & \\
\hline
\end{tabular}

Part 4: Solution on Effects of Noise Pollution at Construction Site

1. Following are the physical and mentally effects that caused by noise pollution at construction site around Klang Valley. Please rate appropriate as below:

Note: 1 = Strongly Disagree, 2 = Disagree, $3=$ Neutral, $4=$ Agree, $5=$ Strongly Agree

\begin{tabular}{|l|l|l|l|l|l|}
\hline Wear Personal Protective Equipment (PPE) & 1 & 2 & 3 & 4 & 5 \\
\hline Prediction of noise pollution during planning stage & & & & & \\
\hline $\begin{array}{l}\text { Applying silencer/ muffler on construction machinery } \\
\text { and equipment }\end{array}$ & & & & & \\
\hline $\begin{array}{l}\text { Construct noise barrier around construction area } \\
\text { (Engineering Control) }\end{array}$ & & & & & \\
\hline $\begin{array}{l}\text { Hire more workers to reduce the exposure time of } \\
\text { noise pollution (Administrative Control) }\end{array}$ & & & & & \\
\hline $\begin{array}{l}\text { Choose quieter model of equipment or device on } \\
\text { market }\end{array}$ & & & & & \\
\hline $\begin{array}{l}\text { Setting a limitation on time period and frequency of } \\
\text { noise pollution }\end{array}$ & & & & & \\
\hline Replacing old machinery with new model & & & & & \\
\hline $\begin{array}{l}\text { Well maintaining construction equipment and } \\
\text { device }\end{array}$ & & & & & \\
\hline
\end{tabular}

